\title{
Genetic analysis of inferior nurturing ability in RR mice
}

\author{
J. Suto ${ }^{1}$, H. Yamanaka² and K. Sekikawa ${ }^{1}$ \\ ${ }^{1}$ Department of Molecular Biology and Immunology, National Institute of Agrobiological \\ Sciences, Tsukuba, Ibaraki 305-8602, Japan; and ${ }^{2}$ National Agricultural Research \\ Organization, Tsukuba, Ibaraki 305-8517, Japan
}

Females of the inbred mouse RR strain have a limited ability to nurture their offspring, and frequently the young die during rearing. Quantitative trait locus analysis was carried out on the $F_{2}$ progeny produced from a genetic cross between RR and KK, a strain of normal nurturing ability, to elucidate the putative genetic basis governing certain aspects of the inferior nurturing ability in the RR strain. One hundred and ninety-two $F_{2}$ female mice were mated with $\mathrm{C57BL} / 6$ J males. After the number of newborns was adjusted to six per dam, nurturing ability was evaluated on the basis of litter

\section{Introduction}

Defects in genes related to reproductive ability may lead to reproductive abnormalities, as illustrated by spontaneously occurring and engineered mutant mice (Doolittle et al., 1996; Nishimori and Matzuk, 1996). In general, these mutants are useful for revealing the genetic bases of reproduction. However, the mutant phenotypes are often developed beyond the normal physiological range and therefore do not always reflect the common aspects of the traits. Reproductive traits, such as ovulation rate, embryonic mortality, litter size, duration of gestation and birth interval, are quantitative traits that are controlled by multiple genes under the influence of environmental stimuli (Land, 1984). Quantitative trait loci (QTL) that control some of these traits have been mapped in cattle, pigs and rats (Rathje et al., 1997; Wilkie et al., 1999; Zidek et al., 1999; Kirkpatrick et al., 2000).

Maternal nurturing ability is the capacity to raise and protect offspring through lactation. Normal nurturing requires an adequate interaction between the mother and the young that comprises complex physiological and behavioural processes (Nowak et al., 2000). Inadequate mother-young interaction or inappropriate maternal care of the offspring during the neonatal period leaves neonates vulnerable and their mortality increases.

Inbred mouse RR mothers have a limited ability to nurture their pups but possess no other gross defects with regard to reproductive performance (Festing, 1996; J. Suto, H. Yamanaka and K. Sekikawa, unpublished). Although pregnancies normally continued to term, the newborn young had a low rate of survival until weaning (weaning rate was $69.6 \%$ with respect to the number of offspring, and

Email: jsuto@nias.affrc.go.jp weight at days 7,12 and 21 after parturition. The results showed that 147 of the $192 F_{2}$ dams were able to rear all six pups, although the litter weight varied considerably among litters. Significant evidence for linkage was identified on chromosome 5 near the microsatellite marker of D5Mit161 for litter weight at $\mathbf{1 2}$ days after parturition. The $\mathbf{R}$ allele (RR strain) at this locus was recessive to the K allele (KK strain), and reduced the litter weight. It is suggested that this locus is one of the heritable components that determine the inferior nurturing ability of RR mice.
$50 \%$ of dams lost pups). Although in depth behavioural studies have not been conducted, RR females do not exhibit overt maternal neglect. Thus, it was hypothesized that the underlying defect is related to poor nutritional support (that is, poor lactation) rather than a behavioural defect.

The aim of the present study was to identify using QTL analysis the gene or genes that control the inferior nurturing ability in RR mice.

\section{Materials and Methods}

Mice and $F_{2}$ production

All mice used in the present study were of inbred strains. KK females and C57BL/6) males were purchased from CLEA JAPAN Inc. (Tokyo). The RR strain had been maintained in the authors' laboratory, and consisted of more than 125 generations of brother-sister mating. The RR strain was derived from Japanese fancy mice and was obtained from a dealer in Sendai, Japan (Festing, 1996). The KK strain was established in Japan by K. Kondo (Festing, 1996) as a diabetic strain with moderate obesity; however, because of the maturity onset nature of the diabetes and obesity, the influence of obesity and diabetes on fertility at younger ages seems to be negligible, particularly in female mice. Hereafter, we define the RR strain as having R alleles, and the KK strain as having $\mathrm{K}$ alleles, throughout the genome.

$\mathrm{KK}$ females were crossed with RR males to produce $\mathrm{KK} \times$ $R R F_{1}$, which were intercrossed to produce the $K K \times R R F_{2}$. On the basis of abdominal expansion, pregnant $F_{1}$ mice were housed individually to produce $F_{2}$ mice. All $F_{2}$ females were weaned at day 30 after birth, and three mice were housed together in each cage.

All mice were maintained in a temperature-controlled 
$\left(22 \pm 3^{\circ} \mathrm{C}\right)$, specific-pathogen-free room, with a regular light cycle of $12 \mathrm{~h}$ light: $12 \mathrm{~h}$ dark and a relative humidity of $50 \%$. Rodent pellet chow (CE-2; CLEA Japan Inc.) and tap water were available ad libitum.

\section{Evaluation of nurturing ability}

As nurturing ability is a difficult parameter to measure, litter weight was used as an indirect, but reliable, measurable characteristic in this study. The use of litter weight as an indicator of nurturing ability is justified as follows. (i) The total body weight of a litter has been used as an indirect measure of a mother's milk production. Growth of pups has been shown to be attributable purely to milk obtained from the dam up to day 12 after birth (Falconer, 1947). (ii) The nursing ability of a mother can be measured by the body weight of her young at day 12 after birth, subsequent to the standardization of the litter size at birth (Nagai, 1975; Nagai et al., 1978).

Three virgin $F_{2}$ female mice had been placed together per cage until day 70 of age, and then a C57BL/6J male of the same age was introduced into each cage. The pregnant $\mathrm{F}_{2}$ females were then caged individually. On the day of delivery, pups were culled randomly or were supplemented with pups from other litters of the same date of birth, to an average of six pups per dam. Nurturing ability was evaluated on the basis of the total litter weight of six pups at days 7, 12 and 21 after birth. Low litter weight was considered an indication of inferior nurturing. An analysis was carried out on dams $(n=147)$ that reared all six pups successfully and a second analysis was carried out on all dams $(n=159)$ regardless of whether pups were lost during rearing. In the second analysis, because the microsatellite genotypes could not be examined on the 12 dams that lost some or all of the pups, genotypes are labelled as missing data.

\section{Microsatellite genotyping}

The genotypes of a total of 75 (69 autosomal and 6 Xlinked) microsatellite markers were determined (Table 1 ). Microsatellite sequence length polymorphism was detected by electrophoresis subsequent to polymerase chain reaction (PCR). Most microsatellite primers were purchased as MapPairs (Research Genetics, Huntsville, AL), whereas others were synthesized. Amplification was carried out with a Takara PCR thermal cycler MP (Takara Biomedicals, Tokyo) under the following conditions: one cycle at $94^{\circ} \mathrm{C}$ for $5 \mathrm{~min} ; 35$ cycles at $94^{\circ} \mathrm{C}$ for $30 \mathrm{~s}, 55^{\circ} \mathrm{C}$ for $1 \mathrm{~min}$ and $72^{\circ} \mathrm{C}$ for $45 \mathrm{~s}$; one cycle at $72^{\circ} \mathrm{C}$ for $7 \mathrm{~min}$. All PCR products were subjected to electrophoresis on $10 \%(\mathrm{w} / \mathrm{v})$ polyacrylamide gels and identified by ethidium bromide staining.

\section{Quantitative trait locus (QTL) mapping and statistical data analysis}

Subsequent to the measurement of phenotypic variables and microsatellite genotyping, QTL analysis was carried out with the Mapmaker/EXP version 3.0b and the Mapmaker/
QTL version 1.1b computer programs (Lander et al., 1987). The chromosomal region with a logarithm of odds (LOD) score of more than 4.3 (threshold of statistical significance at $\alpha=0.05$ ) was recognized as significant linkage, and the region with a LOD score between 2.8 and 4.3 was recognized as suggestive of linkage (Lander and Kruglyak, 1995). The $\alpha$ level for suggestive linkage implies the expectation that there will be one false positive in a genome-wide search. The mode of inheritance in each QTL was determined by comparison of the dominant, recessive and additive models given by the Mapmaker/QTL program, in which a LOD score of 1.0 or a greater difference was used as the criterion. The statistical difference of means among the three genotypes partitioned by the closest marker that flanks the putative QTL was analysed by oneway ANOVA.

\section{Results}

\section{Breeding results in parental strains, $F_{1}$ and $F_{2}$}

The breeding data on parental $R R, F_{1}$ and $F_{2}$ mice, together with (female $R R \times$ male $K K$ ) $F_{1}$ data for comparison, are shown (Table 2). According to the breeding data on KK mice from more than 500 litters provided by CLEA JAPAN, the weaning rate is $97.0 \%$, and the average litter size is 6.2 (litter size was culled randomly to eight pups per dam). The data on parental RR were based on the breeding data compiled in the authors' laboratory, and the number of pups was culled to six at the day of birth. Reciprocal $F_{1}$ crosses were made (culling was not carried out) and the results of both types of $F_{1}$ dams are presented. Although the litter size in $\mathrm{F}_{1}$ was twice as large as that in the parental RR and KK strains, and no adjustment of the number of pups was made, the $F_{1}$ mice exhibited reasonably good nurturing ability. Thus, inferior nurturing ability is inherited on an overall recessive mode. The $F_{1}$ cross of KK females $\times$ RR males was used to generate $F_{2}$ animals. For the $F_{2}$ analysis, the number of pups was adjusted to six per dam at birth.

\section{Evaluation of nurturing ability in F2 mice}

Of $192 \mathrm{~F}_{2}$ females mated with C57BL/6J males, 165 gave birth. The average litter size was $8.5 \pm 2.9$ (mean \pm SD, range $0-15)$. The number of pups was adjusted to six per dam by culling of the extra pups in most litters (136 of 165 litters, $82.4 \%$ ). Of the 165 dams, six died accidentally during rearing, and 12 lost some or all ( $n=1-6$ ) of their pups during rearing. The number of days from the introduction of a C57BL/6) male to parturition was $41.0 \pm 10.0$ (mean $\pm \mathrm{SD}$, range 29-73 days).

The litter weights of six pups from 147 litters (in which all six pups were reared) on days 7,12 and 21 are presented as scatter plots (Fig. 1). The means \pm SD of the litter weights are as follows: $31.49 \pm 3.59 \mathrm{~g}$ (range 19.61-39.6) on day 7 , $45.84 \pm 6.27 \mathrm{~g}$ (range 24.23-58.27) on day 12 and $71.89 \pm 8.49 \mathrm{~g}$ (range 48.11-88.40) on day 21. 
Table 1. Microsatellite markers used and their chromosomal position*

\begin{tabular}{|c|c|c|c|c|c|}
\hline Marker & Position (cM) & Marker & Position (cM) & Marker & Position (cM) \\
\hline \multicolumn{2}{|c|}{ Chromosome 1} & \multicolumn{2}{|c|}{ Chromosome 8} & \multicolumn{2}{|c|}{ Chromosome 14} \\
\hline D1Mit211 & 15 & D8Mit58 & 1 & D14Mit11 & 0.7 \\
\hline D1Mit10 & 56.6 & D8Mit205 & 30 & D14Mit64 & 22 \\
\hline D1Mit102 & 73 & D8Mit267 & 43 & D14Mit94 & 50 \\
\hline D1Mit16 & 87.2 & D8Mit245 & 72 & \multicolumn{2}{|c|}{ Chromosome 15} \\
\hline D1Mit291 & 101.5 & \multicolumn{2}{|c|}{ Chromosome 9} & D15Mit136 & 14.2 \\
\hline \multicolumn{2}{|c|}{ Chromosome 2} & D9Mit9o & 9 & D15Mit63 & 29.2 \\
\hline D2Mit182 & 38.3 & D9Mit229 & 28 & D15Mit190 & 52.8 \\
\hline D2Mit300 & 50.3 & D9Mit107 & 40 & D15Mit35 & 61.7 \\
\hline D2Mit194 & 81.4 & D9Mit182 & 55 & \multicolumn{2}{|c|}{ Chromosome 16} \\
\hline D2Mit346 & 91.8 & & 10 & D16Mit57 & 21.5 \\
\hline \multicolumn{2}{|c|}{ Chromosome 3} & D10Mit123 & 4 & D16Mit139 & 43.1 \\
\hline D3Mit224 & 22 & D10Mit183 & 17 & \multicolumn{2}{|c|}{ Chromosome 17} \\
\hline D3Mit184 & 28 & D10Mit95 & 51 & D17Mit164 & 2.8 \\
\hline D3Mit29 & 45.2 & D10Mit151 & 69 & D17Mit176 & 22.5 \\
\hline \multicolumn{2}{|c|}{ Chromosome 4} & \multicolumn{2}{|c|}{ Chromosome 11} & D17Mit93 & 44.5 \\
\hline D4Mit1 & 6.3 & D11Mit229 & 14 & \multicolumn{2}{|c|}{ Chromosome 18} \\
\hline D4Mit111 & 21.9 & D11Mit86 & 28 & D18Mit177 & 20 \\
\hline D4Mit251 & 66 & D11Mit219 & 43 & D18Mit149 & 24 \\
\hline \multicolumn{2}{|c|}{ Chromosome 5} & D11Mit124 & 57.8 & D18Mit152 & 37 \\
\hline D5Mit200 & 36 & D11Mit61 & 70 & D18Mit162 & 50 \\
\hline D5Mit240 & 59 & \multicolumn{2}{|c|}{ Chromosome 12} & \multicolumn{2}{|c|}{ Chromosome 19} \\
\hline D5Mit161 & 70 & D12Mit136 & 13 & D19Mit68 & 6 \\
\hline D5Mit221 & 78 & D12Mit190 & 28 & D19Mit55 & 53 \\
\hline \multicolumn{2}{|c|}{ Chromosome 6} & D12Mit158 & 38 & \multicolumn{2}{|c|}{ Chromosome $X$} \\
\hline D6Mit116 & 5.5 & D12Mit28 & 52 & DXMit89 & 3 \\
\hline D6Mit123 & 29 & & 13 & DXMit166 & 15.5 \\
\hline D6Mit261 & 37 & D13Mit207 & 9 & DXMit172 & 48.7 \\
\hline \multicolumn{2}{|c|}{ Chromosome 7} & D13Mit221 & 30 & DXMit149 & 50 \\
\hline D7Mit76 & 3.4 & D13Mit110 & 47 & DXMit38 & 53.2 \\
\hline D7Mit232 & 26.8 & D13Mit78 & 75 & DXMit121 & 67 \\
\hline D7Mit253 & 52.8 & & & & \\
\hline D7Mit259 & 72 & & & & \\
\hline
\end{tabular}

*Chromosomal position was retrieved from the Mouse Genome Database (MGD) on 20 November 2000.

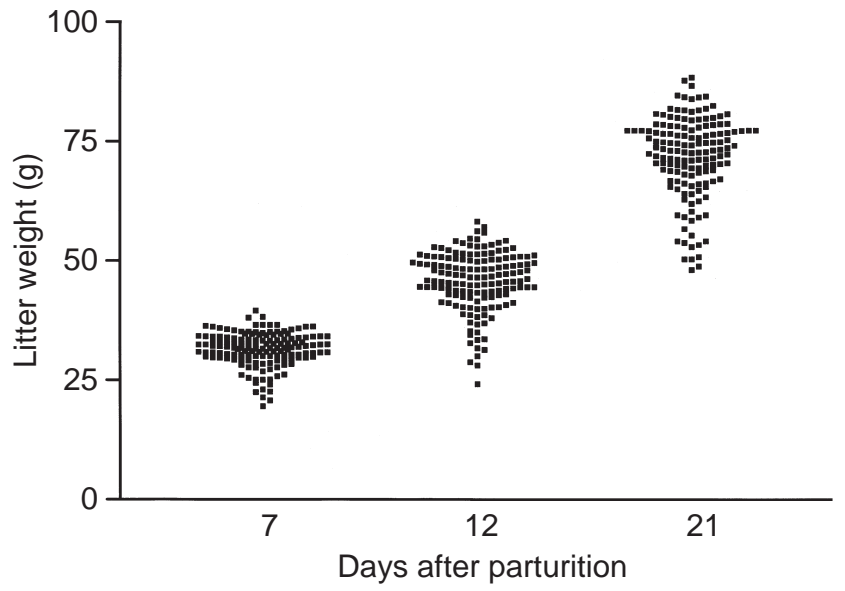

Fig. 1. Scatter plots of litter weight (total weight of six pups) in 147 $\mathrm{F}_{2}$ litters produced from a genetic cross between RR and KK mice at days 7,12 and 21 after parturition.
QTL analysis

Seventy-five microsatellite markers (Table 1) were genotyped in all $\mathrm{F}_{2}$ mice, resulting in an average spacing of $21.3(1600 / 75)$ cM between markers. Thus, the marker density may have been insufficient to detect QTL in chromosomal regions with widely spaced markers. These regions should be analysed in a future analysis.

In an analysis of the 147 dams that reared six pups, statistically significant evidence for linkage was identified on chromosome 5 with a LOD score of 4.5 for litter weight at day 12, near the microsatellite marker of D5Mit161 (Table 3, Fig. 2 ). This locus explained $13.7 \%$ of the $F_{2}$ variance, with an additive effect of $-3.18 \mathrm{~g}$ total litter weight per $\mathrm{R}$ allele. With regard to the litter weight at day 21, this locus showed suggestive evidence for linkage, with a LOD score of 4.0. The $\mathrm{R}$ allele at this locus was recessive to the K allele, and reduced the litter weight (Table 4), consistent with the results of the $F_{1}$ intercrossing. The gene symbol Naq1 (nurturing ability QTL 
Table 2. Comparison of breeding data in dams from $R R, F_{1}$ and $F_{2}$ mice

\begin{tabular}{|c|c|c|c|c|c|}
\hline Dams & $\begin{array}{l}\text { Number of } \\
\text { litters }\end{array}$ & $\begin{array}{l}\text { Number of } \\
\text { pups born }\end{array}$ & $\begin{array}{c}\text { Number of } \\
\text { pups weaned }\end{array}$ & $\begin{array}{c}\text { Weaning } \\
\text { rate }(\%)\end{array}$ & $\begin{array}{l}\text { Average } \\
\text { litter size }\end{array}$ \\
\hline $\mathrm{RR}^{*}$ & 83 & $553(445)$ & 287 & 64.5 & 6.7 \\
\hline$\left(\mathrm{KK}\right.$ female $\times$ RR male) $\mathrm{F}_{1}$ & 20 & 224 & 223 & 99.6 & 11.2 \\
\hline (RR female $\times$ KK male) $F_{1}$ & 8 & 86 & 85 & 98.8 & 10.8 \\
\hline $\mathrm{F}_{2}$ & 165 & $1410\left(990^{* *}\right)$ & 914 & 92.3 & 8.5 \\
\hline
\end{tabular}

*Data were compiled only from litters with more than five pups.

**Number of pups was culled to six per dam at birth (number of pups after culling is indicated in parentheses).

Table 3. Identification of quantitative trait loci (QTL) for litter weight

\begin{tabular}{|c|c|c|c|c|c|}
\hline Chromosome & Closest marker & Traits & LOD score & Variance explained (\%) & Gene symbol \\
\hline 5 & D5Mit161 & Litter weight at 12 days & 4.5 & 13.7 & Naq1 \\
\hline 5 & D5Mit161 & Litter weight at 21 days & 4.0 & 11.7 & \\
\hline 9 & D9Mit9o & Litter weight at 21 days & 3.2 & 9.6 & \\
\hline
\end{tabular}

Naq1: nurturing ability QTL number 1.

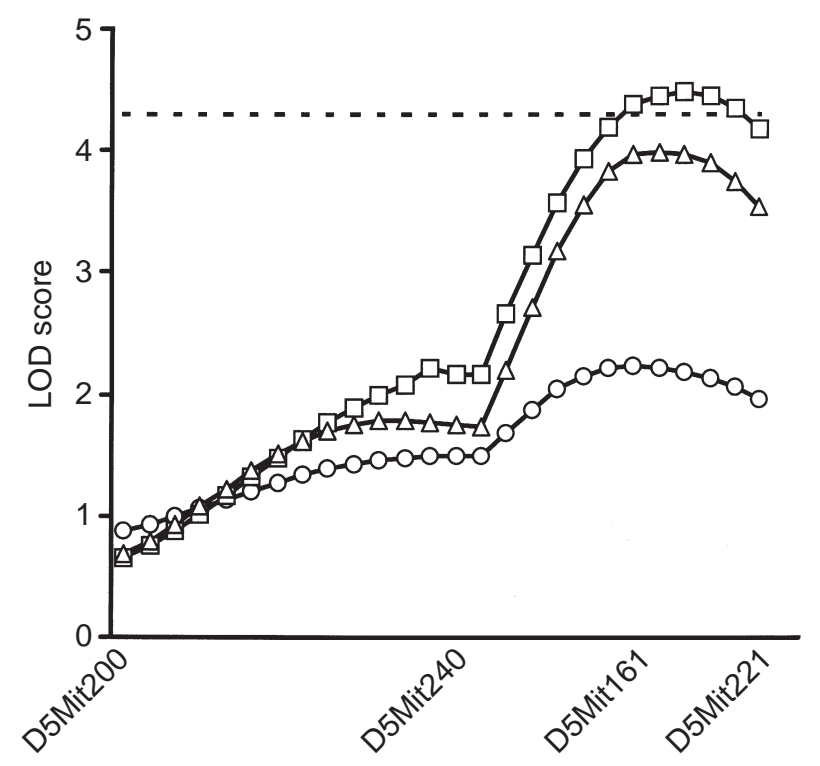

Fig. 2. Identification of nurturing ability quantitative trait locus (QTL) (Naq1) on mouse chromosome 5. Logarithm of odds (LOD) scores for litter weight are given at days $7(\bigcirc), 12(\square)$ and $21(\triangle)$ after birth. Significant linkage was identified for litter weight at day 12 , and suggestive linkage was identified for litter weight at day 21. The lines were based on a free genetic model given by constrained genetic models of the Mapmaker/QTL program. The horizontal dotted line (LOD score 4.3) indicates the threshold of statistical significance $(P=0.05)$.

number 1) was assigned to this locus. The Naq1 is located near the genes encoding zona pellucida protein 3 (Zp3), zonadhesin (Zan), and a disintegrin and metalloproteinase domain 1a (Adam1a) (Kozak and Stephenson, 1998). Zp3 and Adam1a have roles in fertilization of the oocyte (Doolittle et al., 1996; Wolfsberg and White, 1996), whereas Zan is expressed in haploid spermatids (Hardy and Garbers, 1995). Another locus was identified on proximal chromosome 9 for pup weight at day 21, near the microsatellite marker of D9Mit90 with a LOD score of 3.2. Although the linkage was merely suggestive, the $\mathrm{R}$ allele at this locus was dominant to the $\mathrm{K}$ allele and reduced the litter weight (Tables 3 and 4). Although the levels of linkage were not identified for other traits, such as litter size and days to parturition, the influence of Naq1 on these traits was also examined. The Naq1 genotype was found to be associated with litter size, and homozygotes produced significantly fewer pups: KK: $9.1 \pm 2.8(n=38) ; \mathrm{KR}$ (heterozygote): $9.2 \pm 2.3(n=75) ; \mathrm{RR}$ : $7.7 \pm 3.0(n=34)$ (means $\pm \mathrm{SD}, P<0.03$ on a single point statistical basis (Lander and Kruglyak, 1995)). Therefore, the mode of inheritance of the $\mathrm{R}$ allele at the Naq1 locus is recessive to the $\mathrm{K}$ allele and reduced the number of newborn pups.

In the alternative analysis of 159 dams (the abovementioned 147 dams plus 12 dams that lost some or all of their pups), statistically significant evidence for linkage was identified on chromosome 5, with a LOD score of 4.7 for litter weight at day 12, near the microsatellite marker of D5Mit 161. This locus explained $22.8 \%$ of the $F_{2}$ variance, with an additive effect of $-5.62 \mathrm{~g}$ total litter weight per $\mathrm{R}$ allele. This locus showed suggestive evidence for linkage on litter weight at day 21, with a LOD score of 4.2. However, a locus on chromosome 9 did not show even suggestive evidence for linkage at any points of measurement. Thus, when the litter weight data from dams that lost pups were included in the analysis, the LOD score on the Naq1 (chromosome 5) locus became higher, which explains the larger variance compared with that of the chromosome 9 locus. 
Table 4. Results of ANOVA

\begin{tabular}{|c|c|c|c|c|c|c|}
\hline \multirow[b]{2}{*}{ Marker } & \multirow[b]{2}{*}{ Traits } & \multicolumn{3}{|c|}{ Genotype } & \multirow{2}{*}{$\begin{array}{l}\text { Nominal } P \\
\text { value* }^{*}\end{array}$} & \multirow{2}{*}{$\begin{array}{c}\text { Mode of } \\
\text { inheritance of } \\
\text { the R allele }\end{array}$} \\
\hline & & $\mathrm{RR}$ & RK & KK & & \\
\hline D5Mit161 & $\begin{array}{l}\text { Litter weight at } \\
12 \text { days }\end{array}$ & $\begin{array}{c}41.9 \pm 7.1 \\
(34)\end{array}$ & $\begin{array}{l}46.5 \pm 5.4 \\
(75)\end{array}$ & $\begin{array}{c}48.1 \pm 5.6 \\
(38)\end{array}$ & $P<0.00005$ & Recessive \\
\hline D5Mit161 & $\begin{array}{l}\text { Litter weight at } \\
21 \text { days }\end{array}$ & $\begin{array}{c}66.7 \pm 10.2 \\
(34)\end{array}$ & $\begin{array}{c}72.9 \pm 7.0 \\
(75)\end{array}$ & $\begin{array}{c}74.5 \pm 7.7 \\
(38)\end{array}$ & $P<0.0002$ & Recessive \\
\hline D9Mit90 & $\begin{array}{l}\text { Litter weight at } \\
21 \text { days }\end{array}$ & $\begin{array}{c}69.7 \pm 8.6 \\
(32)\end{array}$ & $\begin{array}{c}70.6 \pm 8.8 \\
(75)\end{array}$ & $\begin{array}{c}76.1 \pm 6.4 \\
(40)\end{array}$ & $P<0.0007$ & Dominant \\
\hline
\end{tabular}

Values in parentheses indicate the number of mice.

*The genome-wide threshold for statistical significance in an $\mathrm{F}_{2}$ intercross is a LOD score of 4.3 , corresponding to a $P$ value of $5.2 \times 10^{-5}$ (Lander and Kruglyak, 1995).

\section{Discussion}

Heritable factors are thought to determine the predisposition to low fertility (Land, 1984). Females of the RR strain are apparently inferior in their ability to nurture their offspring (J. Suto, unpublished). In about $50 \%$ of RR litters, some of the newborn young do not survive to weaning and there is an overall $64.5 \%$ weaning rate. This low weaning rate seems to be a consequence of poor maternal nurturing ability rather than high mortality of the RR pups, although this has not been validated conclusively. RR dams tend to provide poor nurturing of $F_{1}$ pups produced from sires of other inbred strains; however, dams from other inbred strains mated with an RR sire nurtured young normally. In the $F_{2}$ generation in the present study, six dams (3.6\%) died while rearing their young, indicating that it is a considerable burden for them to nurture their offspring. In contrast, none of the 27 non-pregnant females died. Furthermore, the litter weight varied considerably among the litters but weight differences among individual pups were not so prominent. RR mice were not inferior to other mouse strains with regard to other reproductive traits, such as litter size, sex ratio or days required for the first delivery. Therefore, RR mice are a particularly useful animal model for investigating the genetic cause of the impaired maternal nurturing, because the trait can be examined without having to take into consideration other traits that may influence the nurturing ability. For clarification of the limited nurturing ability, further behavioural studies will be required. However, the underlying defect is likely to be related to poor lactating ability rather than a behavioural defect, because RR females do not exhibit overt maternal neglect. Poor lactating ability may be the single major defect in RR mice but it is also possible that pups of the RR strain have some inherent congenital defects. It is hoped that this possibility can be tested in the near future by cross-fostering between RR and KK strains, and postmortem examination of pups.

In the present study, a significant QTL was identified for nurturing ability (total body weight of 6 pups at day 12 after birth) on chromosome 5, and there were two possible linkages on chromosome 5 and chromosome 9 (both for litter weight at day 21). In the region neighbouring the QTL on chromosome 5, there are loci that pertain to reproduction (Kozak and Stephenson, 1998). The first locus contains zona pellucida protein 3 (Zp3). Zp3 knockout mice have been established and the females were found to be infertile (Rankin et al., 1996). Therefore, the possibility that $Z p 3$ plays a role in maternal behavior remains unanswered. The second locus is for zonadhesin (Zan), which encodes a sperm membrane protein (Hardy and Garbers, 1995). The third locus is for a disintegrin and metalloproteinase domain 1a (Adam1a, fertilin alpha), a member of the Adam gene family. There are several ADAMs proteins that operate during fertilization and development (Wolfsberg and White, 1996). Although Zp3, Zan and Adam1a are involved in certain aspects of fertility, there is no evidence to indicate that they affect the maternal ability to nurture.

Although no separate QTLs responsible for litter size were identified in the present study, the fact that the genetic locus responsible for nurturing also has an influence on litter size indicates that these distinct variables share a common basis. Furthermore, the R allele at the Naq1 locus was recessive for both nurturing ability and litter size.

Genetic studies on several knockout mice, such as studies on fos $B$ (FBJ osteosarcoma oncogene B, chromosome 7) (Brown et al., 1996), Prlr (prolactin receptor, chromosome 15) (Lucas et al., 1998) and Oxt (oxytocin, chromosome 2) (Nishimori et al., 1996) have demonstrated that the maternal behaviour of nurturing is regulated genetically. These studies indicate that numerous genes may influence maternal behavior. The fact that nurturing ability in RR mice is not as limited as in the abovementioned knockout mice may lead to difficulties in defining the major reason for poor nurturing.

The fact that a higher LOD score was obtained on the Naq1 (chromosome 5) locus when the analysis included dams that had lost pups increases the probability of the existence of the Naq1 QTL. The existence of the QTL was 
confirmed in a second analysis that reflects the defective nature of the RR, that is, that RR female mice wean a smaller percentage of pups and litters. However, the analysis that included dams that lost pups did not detect even a suggestive linkage on chromosome 9.

The results of the present study indicate that there are genetic components, as yet unidentified in other mutant mouse systems, which control poor nurturing ability in the RR strain.

Identification of loci that control reproductive behaviour will lead to better understanding of maternal behaviour and will assist in the successful reproduction of laboratory animals and economically important livestock.

The authors thank CLEA Japan Inc., Tokyo, Japan, for providing breeding data on several inbred strains. This work was supported by a grant from the Ministry of Agriculture, Forestry and Fishery, Japan.

\section{References}

Brown JR, Ye H, Bronson RT, Dikkes P and Greenberg ME (1996) A defect in nurturing in mice lacking the immediate early gene fosB Cell $\mathbf{8 6}$ 297-309

Doolittle DP, Davisson MT, Guidi JN and Green MC (1996) Catalog of mutant genes and polymorphic loci. In Genetic Variants and Strains of the Laboratory Mouse Vol. 1 3rd Edn pp 17-854 Eds MF Lyon, S Rastan and SDM Brown. Oxford University Press, Oxford

Falconer DS (1947) Milk production in mice Journal of Agricultural Science 37 224-235

Festing MFW (1996) Origins and characteristics of inbred strains of mice. In Genetic Variants and Strains of the Laboratory Mouse Vol. 2 3rd Edn pp 1537-1576 Eds MF Lyon, S Rastan and SDM Brown. Oxford University Press, Oxford

Hardy DM and Garbers DL (1995) A sperm membrane protein that binds in a species-specific manner to the egg extracellular matrix is homologous to von Willebrand factor Journal of Biological Chemistry 27026 025-26 028

Kirkpatrick BW, Byla BM and Gregory KE (2000) Mapping quantitative trait loci for bovine ovulation rate Mammalian Genome 11 136-139

Kozak CA and Stephenson DA (1998) Mouse chromosome 5 Mammalian Genome 8 S91-S113

Land RB (1984) Genetics and reproduction. In Reproduction in Mammals Vol. 4 2nd Edn Reproductive Fitness pp 62-102 Eds CR Austin and RV Short. Cambridge University Press, Cambridge
Lander E and Kruglyak L (1995) Genetic dissection of complex traits: guidelines for interpreting and reporting linkage results Nature Genetics $11241-247$

Lander ES, Green P, Abrahamson J, Barlow A, Daly MJ, Lincoln SE and Newburg L (1987) MAPMAKER: an interactive computer package for constructing primary genetic linkage maps of experimental and natural populations Genomics 1 174-181

Lucas BK, Ormandy CJ, Binart N, Bridges RS and Kelly PA (1998) Null mutation of the prolactin receptor gene produces a defect in maternal behavior Endocrinology 139 4102-4107

Nagai J (1975) Sources of variation in preweaning weight of mice Laboratory Animal Science 25 450-453

Nagai J, Eisen EJ, Emsley JAB and Mcallister AJ (1978) Selection for nursing ability and adult weight in mice Genetics 88 761-780

Nishimori K and Matzuk MM (1996) Transgenic mice in the analysis of reproductive development and function Reviews of Reproduction 1 203-212

Nishimori K, Young LJ, Guo Q, Wang Z, Insel TR and Matzuk MM (1996) Oxytocin is required for nursing but is not essential for parturition or reproductive behavior Proceedings National Academy of Sciences USA 93 11699-11704

Nowak R, Porter RH, Levy F, Pierre O and Schaal B (2000) Role of mother-young interactions in the survival of offspring in domestic mammals Reviews of Reproduction 5 153-163

Rankin T, Familari M, Lee E, Ginsberg A, Dwyer N, Blanchette-Mackie J, Drago J, Westphal H and Dean J (1996) Mice homozygous for an insertional mutation in the Zp3 gene lack a zona pellucida and are infertile Development 122 2903-2910

Rathje A, Rohrer GA and Johnson RK (1997) Evidence for quantitative trait loci affecting ovulation rate in pigs Journal of Animal Science 75 1486-1494

Wilkie PJ, Paszek AA, Beattie CW, Alexander LJ, Wheeler MB and Schook LB (1999) A genomic scan of porcine reproductive traits reveals possible quantitative trait loci (QTLs) for number of corpora lutea Mammalian Genome 10 573-578

Wolfsberg TG and White JM (1996) ADAMs in fertilization and development Developmental Biology 180 389-401

Zidek V, Pintir J, Musilova A, Bila V, Kren V and Pravenec M (1999) Mapping of quantitative trait loci for seminal vesicle mass and litter size to rat chromosome 8 Journal of Reproduction and Fertility 116 329-333

Received 24 July 2000.

First decision 20 October 2000.

Final version received 29 August 2001.

Accepted 10 October 2001. 